\title{
The Growth and Development of Fat Cells in Infancy
}

\author{
T. J. C. BOULTON, MARJORIE DUNLOP, AND J. M. COURT ${ }^{(12)}$
}

Department of Paediatrics, University of Melbourne, and Royal Children's Hospital, Melbourne, Victoria, Australia

\section{Summary}

Studies on the development of adipose tissue in infancy would seem essential to test the hypothesis that adult fat stores relate to the numbers of fat cells developed during early childhood. Thirty infants aged from 1-28 months and 13 fetuses of approximately 11-16 weeks of gestation obtained at therapeutic abortion and two preterm infants of 28 weeks of gestation were studied. The cells of both fetal and infant adipose tissue were separated from connective tissue and fixed by treatment with osmium tetroxide in buffered collidine using a method modified from Hirsch and Gallian ( $J$. Lipid Res., 9: 100 (1968)) for estimation of cell size and number. In fetal and early infancy there are two populations of cells in adipose tissue. Small cells found in tissue before birth and the first months of postnatal life do not contain fat. The larger cells, which are fat containing, represent maturing fat cells. They are cells which include fat cells recognized by previous workers but up to $24.6 \%$ were found to be less than $25 \mu \mathrm{m}$ in diameter. Small cells in the early stages of fat accumulation may make an important contribution to the cell population of fat mass. It is apparent that increasing fat accumulation in the first 6-12 months of life, as demonstrated by increased skinfold thickness measurements, is associated with increasing fat cell size and that this association bears a linear relationship.

\section{Speculation}

Previously unrecognized cells in fetal and infant fat tissue may represent the precursors of mature adipose cells. Establishment of adipose tissue occurs with the development of such cells and the gradual accumulation of fat within the cell until the age of 6-12 months postnatally.

In studies of obesity, increasing emphasis has been placed on the development of adipose tissue during early infancy. Experimental evidence from rats has suggested that early environmental factors may play a part in the subsequent development of adipose tissue cellularity (6). Knittle and Hirsch (5) discussed the role of increased numbers of fat cells in long standing adult obesity. It has been suggested that there is a critical time in the development of fat cells in which multiplication of fat cells may occur in response to overnutrition $(6,7)$, and Brook (2) has produced some evidence that fat cells may increase in number during the first 8 years of childhood. After this age, increase in fat stores is said to depend on increase in the size of fat cells.

There have been few studies on the development of adipose tissue in infancy. Such studies would seem essential to test the hypothesis that adult fat stores relate to the numbers of fat cells developed during early childhood.

In a previous report (3) measurements of fat cell size in normal infants were made using a technique which recognized cells less than $25 \mu \mathrm{m}$ in diameter, a figure usually accepted in other studies as the lower size limit for adipocyte cells $(5,8)$. This report gives further information on studies on adipose tissue from fetuses and normally nourished children, and the clinical correlations between the subjects and the sizes of cells containing fat in adipose tissue.

\section{MATERIALS AND METHODS}

\author{
SOURCE OF MATERIAL
}

Thirty infants aged from 1-28 months were selected for study. All were regarded as healthy and appeared normally nourished. They had been admitted to hospital for minor elective genital or abdominal wall surgery.

The children were weighed and their length measured before surgery. Body mass index was calculated as weight in kilograms
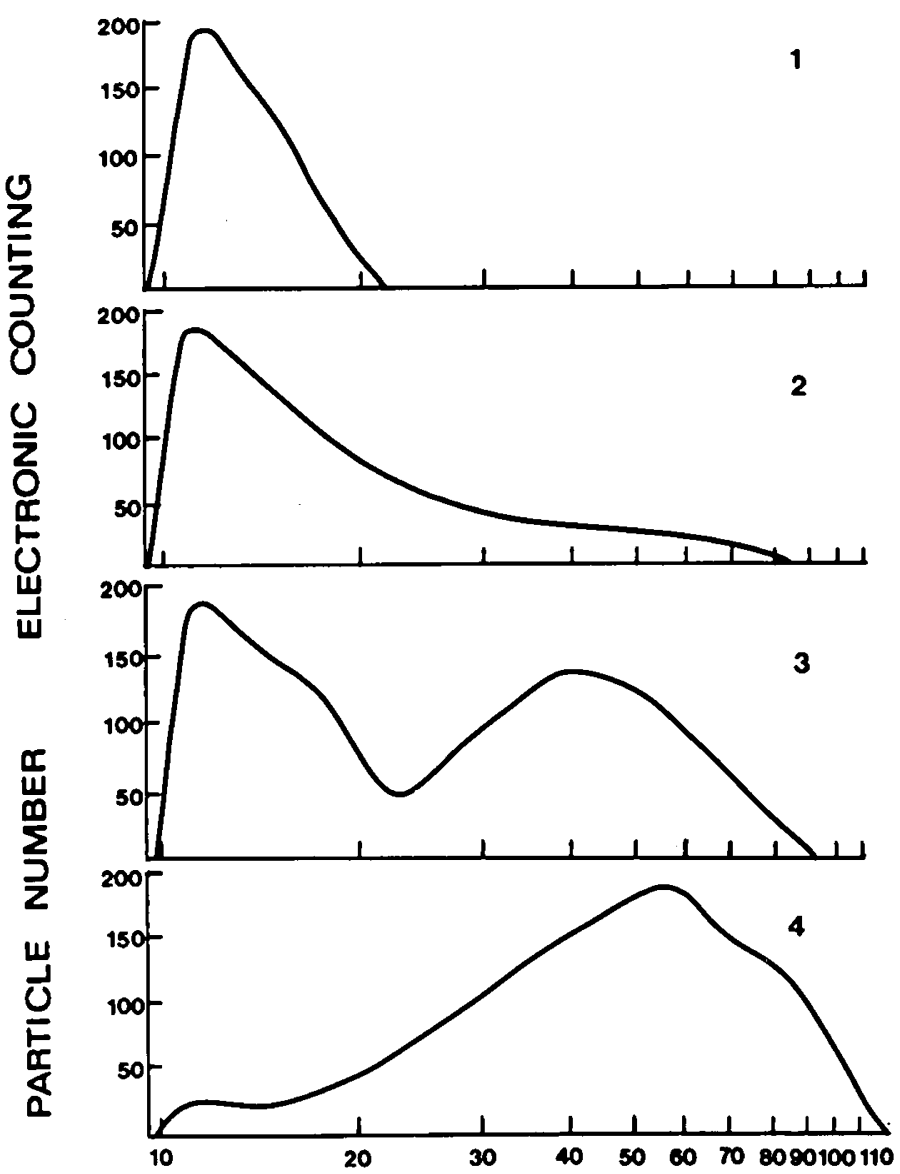

PARTICLE DIAMETER

(MICRONS)

Fig. 1. Representative particle diameter distribution curves: 1 , single peak of small particles found in fetal tissue of 10-24 weeks of gestation; 2, extension of the peak by larger osmium-fixed cells in older fetuses and young infants, 20 weeks of gestation to 2 months of postnatal age; 3 , development of a second peak of larger osmium-fixed cells found in infants 2-28 months of age; 4 , predominance of osmium-fixed cells in infants 4.5-27 months of age. 
divided by height in centimeters squared. Skinfold thickness measurements were made using a Harpenden caliper at the left midtriceps, midbiceps, subscapular, and suprailiac sites. The sum of these measurements was used as an index of adipose tissue stores and to calculate percentage of body weight as fat (1).

Samples of adipose tissue were obtained through the abdominal incision at the start of the elective surgical procedure. All surgery was done under general anesthesia after a 6-hr fast.

In addition, subcutaneous tissue from the anterior abdominal wall of 14 fetuses of approximately 11-16 weeks of gestation obtained at therapeutic abortion for medicosocial reasons and two preterm infants of 28 weeks of gestation who died soon after birth were studied. The gestational age of these subjects was calculated from the date of the mother's last menstrual period and from crown-rump length.

\section{CELL SIZING TECHNIQUES}

The cells of both fetal and infant adipose tissue were separated from connective tissue and fixed by treatment with osmium tetroxide in buffered collidine using a method modified from Hirsch and Gallian (4). Tissue was incubated with buffered osmium tetroxide $(0.5 \% \mathrm{w} / \mathrm{v})$ which had been filtered using a $0.45-\mu \mathrm{m}$ Millipore filter (Millipore Corp., Bedford, MA). After $72 \mathrm{hr}$ of fixation at $37^{\circ}$ the cells were liberated from remaining connective tissue by gentle sieving between two discs of polyester thread cloth. The cells dislodged from the cloth were made up to a known volume with isotonic saline. This was the material used for estimation of cell size and number. Samples of the osmium-fixed preparation were examined microscopically to confirm the integrity of the cells.

A sample of known weight was taken from each tissue sample at the time of collection for estimation of the fat content was percentage of triglyceride. Glycerol trioleate ( $\mathrm{mol} \mathrm{wt} \mathrm{885.4)}$ was used as a standard. Triglyceride was estimated as glyceride-glycerol by the method of Van Handel and Zilversmit (9) on samples of $5-20 \mathrm{mg}$.

The conditions for sizing the cells were chosen to give minimal change in particle number. Osmium-fixed cells in saline electrolyte will settle rapidly. If agitation is chosen to produce a uniform suspension of cells, errors may be introduced from two sources: air bubbles may be included in the suspension, and osmium-fixed cells will adhere to the counting vessel wall, particularly at the electrolyte surface. To avoid the use of a mechanical stirrer, an electrolyte containing glycerol with the same electric resistance as isotonic saline, but with an increased density, was used (8). Using this electrolyte a uniform suspension of cells giving identical cell count and sizing profile on ten aliquots of $500 \mu \mathrm{l}$ taken from one suspension was obtained. Adherence of particles to the vessel wall did not occur, reproduceable results being obtained when the cell suspension was transferred through a series of vessels.

Cell number and cell size profiles were obtained using an Electro Zone Celloscope (Particle Data, Inc., Elmhurst, IL) with a PDP 8E minicomputer incorporated to act through analog to digital conversion as a multichannel analyzer. On this instrument

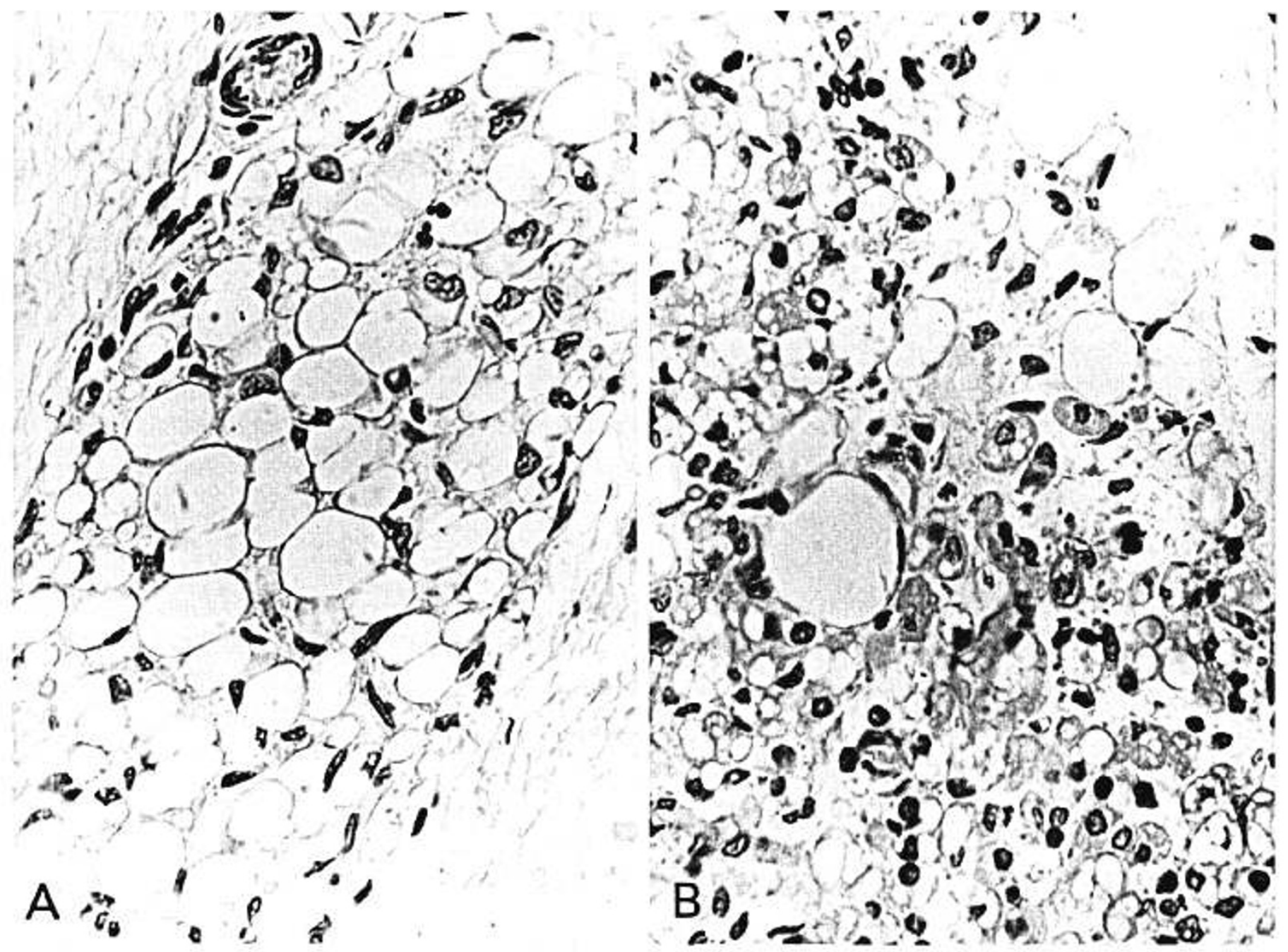

Fig. 2. A hematoxylin and eosin preparation of subcutaneous tissue from an infant born at 28 weeks of gestation. A: Fat cells of varying size are seen. Cells with a peripheral nucleus and cytoplasm are characteristic of the cells of adult adipose tissue. $B$ : many small cells without extensive fat vacuoles are present in the tissue. 
a $300-\mu \mathrm{m}$ sampling orifice was used and cell suspensions were sampled without further filtration. Data was presented in a form of diameter distribution over a callibration range. Final diameter distributions were shown in a logarithmically converted form. The characteristic of fat cell size used for comparison in this study was the modal diameter in microns. Selected samples were also prepared for conventional light microscopy using a hematoxylin and eosin stain.

\section{RESULTS}

\section{SIZE OF PARTICLES IN CELL PREPARATION}

Examination of the distribution curves of cell preparations for each subject showed a considerable change in modal cell size with increasing age of the fetus and child. In addition, there appeared to be more than one population of cells, and on the basis of this observation, the findings could be divided into four different groups of results. These are shown as cell-sizing profiles in Figure 1.

1. In 10 fetuses of gestational age 10-24 weeks, the particle distribution profile consisted of a single peak in which all cells were less than $17.5 \mu \mathrm{m}$ in diameter. Microscopic examination showed that the peak was comprised of particles of connective tissue debris and cells in which osmium fixing was only apparent in the membrane. No centrally osmium-fixed cells were present.

2. In a group of 5 fetuses and infants of gestational age 20 weeks to 2 months postnatal age, the particle distribution profile showed an increasing number of larger cells extending the peak seen in the embryoes and younger fetuses. Microscopic examination showed that in addition to the connective tissues debris and membrane-fixed cells seen in the first group, a number of larger cells with central osmium deposition characteristic of fat cells prepared by this method were seen.

3 . In a third group of 24 infants age $2-28$ months, increasing numbers of larger cells formed a second peak, providing a bimodal distribution of particles. The mean modal value of the second peak in this group was $57.4 \mu \mathrm{m}$ (SD 10.9). Microscopic appearance

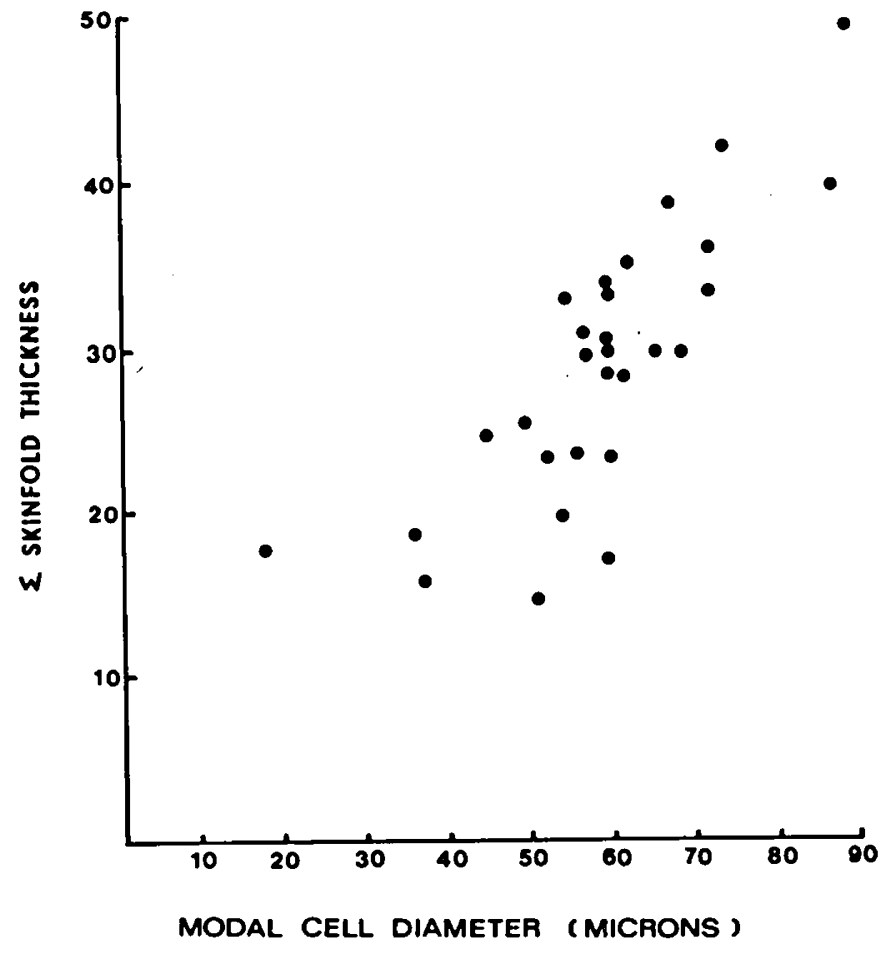

Fig. 3. Relationship between modal cell diameter and degree of fatness, assessed by the sum of four skinfold thickness measurements, of all infants in the study. showed particles similar to those seen in the preceding group but with increasing proportions of larger fat-containing cells.

4. The fourth group, consisting of five infants, age 4.5-27 months of age, had only a single population of larger cells of mean

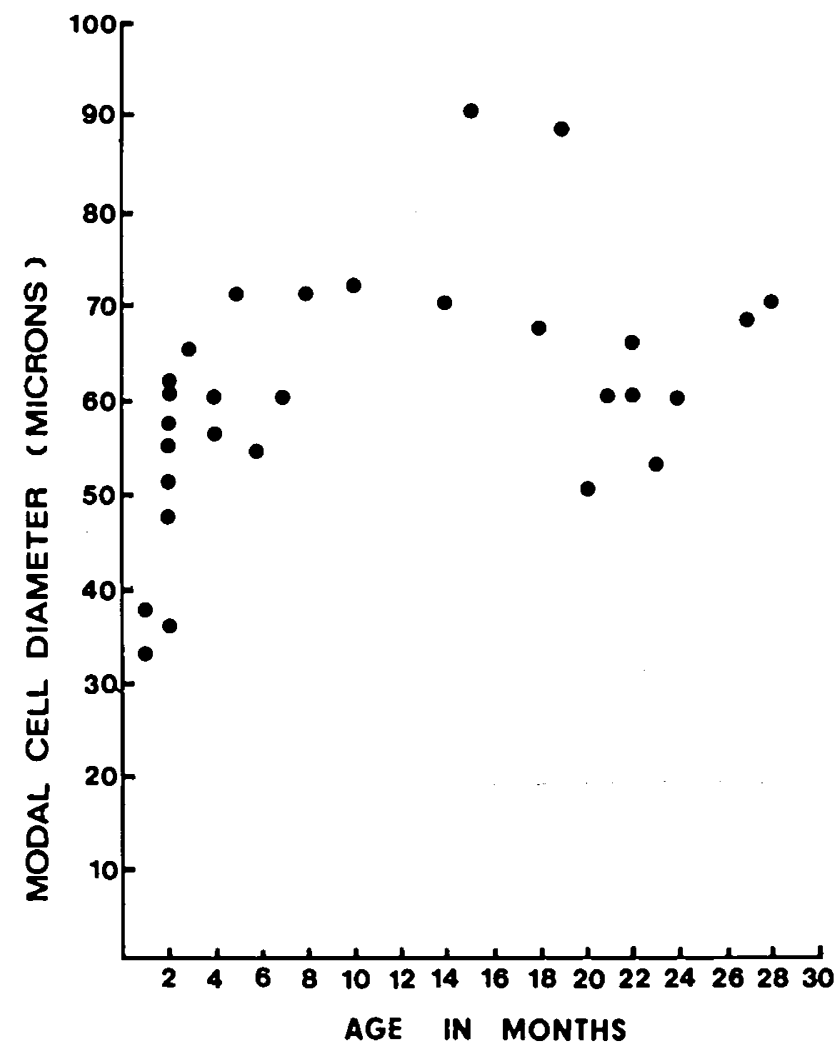

Fig. 4. The relationship of modal cell diameter and infants to age.

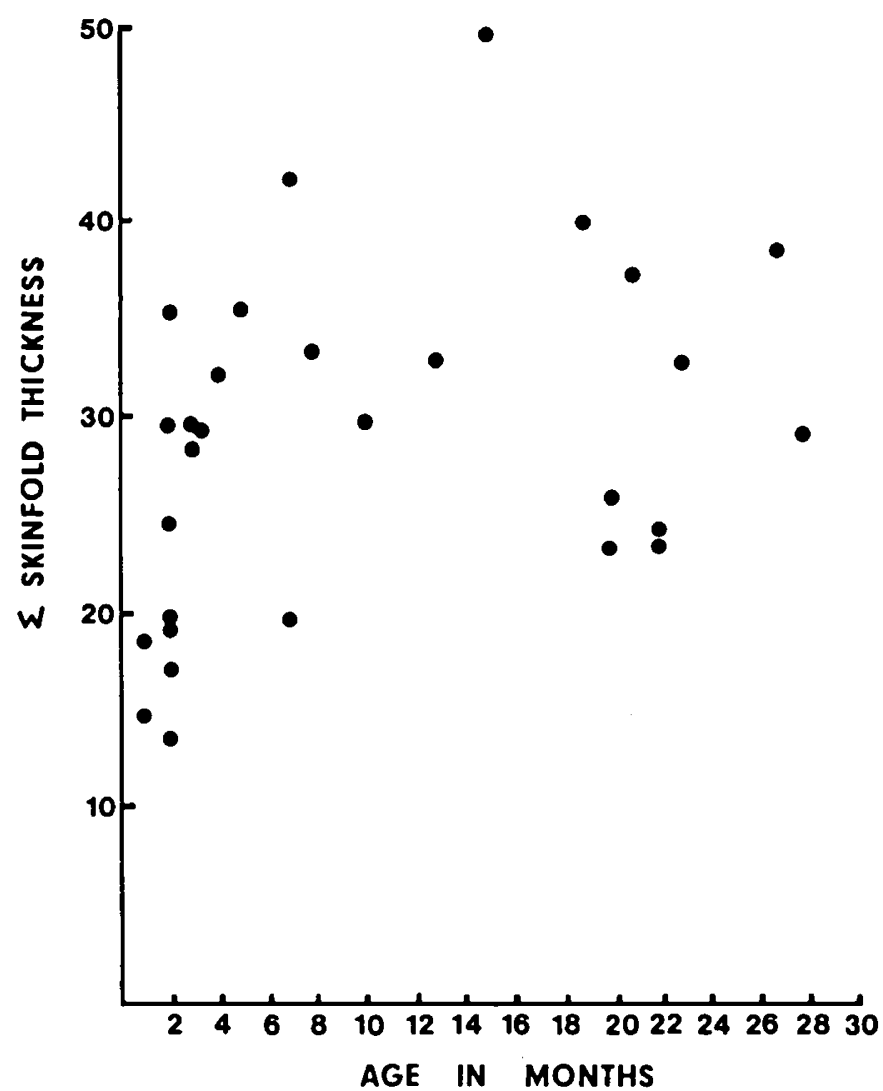

Fig. 5. The relationship of skinfold thickness of infants to age. 
modal distribution of $69.7 \mu \mathrm{m}$ (SD 11.1). The only cells present in this group were fat-containing cells.

The variable size of the cells found in the developing subcutaneous tissue are shown in Figure 2. The preparation of tissue from an infant born at 28 weeks of gestation shows on conventional microscopy, diversity of cell sizes and includes cells without fat vacuolation.

\section{CLINICAL CORRELATION OF FAT-CONTAINING CELLS (SECOND PEAK OF DISTRIBUTION)}

The characteristic of fat cell size which enabled the best comparison with clinical parameters was modal cell size taken directly from the distribution profile of the second peak which contained only osmium-fixed cells. Modal cell diameter at all ages showed a linear correlation with the sum of skinfold thickness measurements $(r=0.83)$ (Fig. 3).

Modal cell diameter increased from birth until the age of 6-8 months. After this age there was no further increase in modal cell diameter until age 28 months (Fig. 4). Body fatness as measured by the sum of skinfold thicknesses showed a similar increase until the age of 6-8 months and then a decrease until the age of 28 months (Fig. 5). Modal cell diameter also showed positive correlation with the body mass index of fatness $(r=0.77)$.

Thus fat cell size and the degree of fatness increase in the first 6 months. The change in degree of fatness is reflected in changing cell size throughout infancy.

\section{DISCUSSION}

These studies show clearly that in the fetus and in early infancy there are two populations of cells in adipose tissue. The small cells, found in tissue before birth and in early postnatal life, do not appear to contain fat and their nature is discussed in a following report.

The larger cells, which are fat containing and constitute the second peak in distribution curves of infants aged 2 months or more, represent maturing fat cells. They are cells which include fat cells recognized by previous workers but up to $24.6 \%$ were found to be less than $25 \mu \mathrm{m}$ in diameter.

Although some studies (9) have recognized the presence of cells below this limit and have used a lower level of detection $(10 \mu \mathrm{m})$ in adult adipose tissue, these cells were not recognized previously in young children, so that some doubt may exist on estimates of total fat cell number based on this technique.

Concepts of critical ages for cell replication and the development of adipose tissue which are based on the recognition of mature fat cells should be reviewed in the light of this finding. Small cells in the early stages of fat accumulation may make an important contribution to the cell population of fat mass. Examination of adipose tissue at other times of fat accumulation, such as in adolescent girls and in adults who are rapidly gaining weight, might also reveal such cells.

Clinical correlations found between the second distribution peak of cells demonstrate the relationship of cell size to developing adipose stores in early infancy. This second peak consists of fatfilled cells and represents cells destined to be mature adipose tissue. It is apparent that increasing fat accumulation in the first 6-12 months of life, as demonstrated by increased skinfold thickness measurements, is associated with increasing fat cell size and that this association bears a linear relationship. It is not possible from these studies to state whether replication of cells is also occurring over this period.

After the age of 6-12 months, the infants studied showed relative diminution of adipose tissue as measured by skinfold thickness, and this may have been reflected in decrease in fat cell size. A correlation between adipose stores and size of the mature fat cell holds true throughout the period of infancy studied.

Any consideration of critical ages for fat cell replication that is based on calculation of numbers of fat cells by previous techniques may need review. Techniques based on counting cells greater than $25 \mu \mathrm{m}$ in diameter may fail to count significant numbers of small fat-filled cells, and disregard the precursor of the adipocyte. Small cells observed with subcutaneous tissue in our study and found in close association with adipose cells may represent such preadipocytes.

\section{REFERENCES AND NOTES}

1. Brook, C. G. D.: Determination of body composition of children from skinfold measurements. Arch. Dis. Childhood, 46: 182 (1971).

2. Brook, C. G. D.: Evidence for a sensitive period in adipose cell replication in man. Lancet, 2: 625 (1972).

3. Boulton, T. J. C., Dunlop, M., and Court, J. M.: Adipocyte growth in the first two years of life. Aust. J. Paediat., 10: 301 (1974).

4. Hirsch, J., and Gallian, E.: Methods for determining adipose cell size in man and animals. J. Lipid Res., 9: 110 (1968).

5. Hirsch, J., and Knittle, J. L.: Cellularity of bese and non-obese adipose tissue. Fed. Proc., 29: 1516 (1970).

6. Knittle, J. L., and Hirsch, J.: Effects of early nutrition on the development of rat epididimal fat pads: Cellularity and metabolism. J. Clin. Invest., 47: 2091 (1968).

7. Salans, L. B., Cushman, S. W., and Weismann, R. E.: Adipose cell size and number in non-obese and obese patients. J. Clin. Invest., 52: 929 (1973).

8. Sjostrom, L., Bjorntorp, P., and Vrana, J.: Microscopic fat cell measurements on frozen-cut tissue in comparison with automated determinations of osmium fixed fat cells. J. Lipid Res., 12: 521 (1971).

9. Van Handel, E., and Zilversmit, D. B.: Micromethod for the direct determination of serum triglycerides. J. Lab. Clin. Med., 50: 152 (1957)

10. We are grateful for the advice of Professor D. B. Cheek in the planning of this study. Surgeons of the Royal Children's Hospital have been most cooperative in providing tissue.

11. Informed consent was obtained from parents of all infants included in this study.

12. Requests for reprints should be addressed to: Dr. J. M. Court, Department of Paediatrics, Royal Children's Hospital, Flemington Road, Parkville, Victoria 3052 (Australia).

13. Received for publication March 28, 1977.

14. Accepted for publication December 12, 1977. 